\title{
Metallic fractures assessments: OCT versus SEM
}

\author{
Gheorghe Hutiu ${ }^{\mathrm{a}}$, Virgil-Florin Duma ${ }^{1 \mathrm{a}, \mathrm{b}}$, Dorin Demian ${ }^{\mathrm{a}}$, Alexandru-Lucian Dimb ${ }^{\mathrm{b}}$, \\ Ralph-Alexandru Erdelyi ${ }^{\mathrm{b}}$, Adrian Bradu $^{\mathrm{c}}$, Adrian Gh. Podoleanu ${ }^{\mathrm{c}}$
}
a3OM Optomechatronics Group, Aurel Vlaicu University of Arad, 77 Revolutiei Ave., 310130 Arad, Romania
boctoral School, Polytechnic University of Timisoara, 1 Mihai Viteazu Ave., 300222 Timisoara, Romania
${ }^{\mathrm{c}}$ Applied Optics Group, School of Physical Sciences, University of Kent, Canterbury, CT2 7NH, United Kingdom

\begin{abstract}
Metals can break either in a ductile or brittle manner if a static or dynamic load is applied to the same material. This depends on a variety of factors, such as the manner in which the load is applied, the shape of the mechanical part, the operating conditions, the nature and structure of the metallic material, and the working temperature. If subjected to variable loads, metallic materials break due to what is called fatigue. The microscopic analysis of fracture surfaces is currently carried out by using scanning electron microscopy (SEM). We have proposed, for the first time to our knowledge, a new method to analyze fracture surfaces, using a low coherence interferometry technique, Optical Coherence Tomography (OCT) [Gh. Hutiu, V.-F. Duma, et al., Surface imaging of metallic material fractures using optical coherence tomography, Appl. Opt. 53, 5912-5916 (2014); Gh. Hutiu, V.-F. Duma, et al., Assessment of ductile, brittle, and fatigue fractures of metals using optical coherence tomography, Metals 8, 117 (2018)]. The present paper presents the way we have demonstrated that OCT can replace the gold standard in such assessments, i.e. SEM, despite the fact that OCT has a resolution of 20 to $4 \mu \mathrm{m}$ (in our investigations), while the SEM we employed has a 4 to $2 \mathrm{~nm}$ resolution. A few examples are given in this respect-for different types of fractures. The advantages of OCT versus SEM are discussed. This development opens the way for in situ investigations, for example in forensic sciences, where OCT can be applied (including with handheld scanning probes. as we have developed). In contrast, SEM, TEM, and AFM are lab-based techniques, more expensive, and they require trained operators.
\end{abstract}

Keywords: metallic materials, fractures, Optical Coherence Tomography (OCT), optical metrology, scanning electron microscopy (SEM), experimentals.

\section{INTRODUCTION}

For the study of metallic materials, laboratories utilize equipment capable to determine images of structure, diffraction patterns and composition:

(i) Various methods and types of equipment are currently utilized for the analysis of the structure of metallic materials. Thus, structural images are obtained using magnifying lens, ordinary optical microscopes, as well as optical microscopes functioning at high temperatures, transmission electron microscopes (TEM), scanning electron microscopes (SEM), reflection electron microscopes, field ion microscopes, atomic force microscopes (AFM) [1-4], etc.

(ii) The diffraction pattern of the crystal lattice is analyzed using other methods, including X-rays, low electron diffraction, neutron diffraction, etc.

(iii) Material compositions are analyzed by using electron microprobes (with electron beams and X-rays), ion microprobes, photoelectron spectrometers, Auger electron spectrometers, etc.

\footnotetext{
${ }^{1}$ Email: duma.virgil@ osamember.org; phone: +40-751-511451; sites: http://3om-group-optomechatronics.ro/; https://www.researchgate.net/lab/3OM-Optomechatronics-Group-Virgil-Florin-Duma
} 
To study the fracture of metallic materials SEM is the gold standard. It is characterized by a very good resolution, in the range of nanometers, but it also has several drawbacks, including high equipment costs, the necessity to have trained operators, and the fact that it is a lab-based technique. The latter aspect implies that it cannot be utilized to perform in situ assessments, as it is required for example in forensic investigations-for example in the case of plane, train, or car accidents, as well as of other incidents, such as blade ruptures of turbines or pipe ruptures. Given the above, we have proposed, for the first time to our knowledge, the use of an IR-based imaging method, Optical Coherence Tomography (OCT) [5,6], to replace SEM in such investigations [7,8]. A low coherence interferometry method, OCT systems have (much) lower costs (roughly by a factor of 20), it does not require trained operators, and it can be utilized in situ, as mobile systems have been constructed. It can also be operated with handheld scanning probes [9-11], to move around a large sample and to image different areas of interest.

According to the literature the following types of (non-medical) materials have been analyzed using OCT:

(i) Plastics and composites [13-18]. Their analysis focused on internal structure, matrices and reinforcement, superficial stress of resin drops, layer thickness, and defects/flaws occurring inside layers.

(ii) As far as dental materials [19-22] are concerned, several aspects have been analyzed: layer/stratum thickness, interlayer and inside the layer defects, as well as layers contraction.

(iii) For electronic materials $[23,24]$, analyses have been carried out concerning thickness of layers, layer flaws/defects, and defects occurring between layers.

(iv) Thickness of layers and defects between layers were also analyzed in glass [25-27].

(v) Analyses of surfaces resulting from various processing techniques have been carried out for different materials [28].

(vi) OCT was also used in paintings [29], in order to analyze structure of paint layers, thickness of layers, as well as sketches existing below paint layers.

In the present paper we present a few analyses of the structure of metallic materials (their fracture surfaces) subjected to tests for ductile, brittle, or fatigue fractures. Due to space limitations, only a few elements of the extended studies we have been carrying on in $[7,8]$ are pointed out.

\section{ANALYSIS OF FRACTURES}

The major scopes of the analysis of fracture surfaces are to determine the causes that generate damage of machinery parts, to obtain new information regarding the structure of solid bodies, to optimize machinery design, and to improve metallic material manufacturing technologies.

Metallic materials fractures can be classified according to several criteria: crystallographic manner of fracture, aspect of fracture, and aspect of the plastic deformation preceding the fracture. According to the crystallographic fracture manner (the tensile stress generating them), fractures can be:

a) sliding/cleavage fractures when the aspect of the fracture crack is bright crystalline. Fracture due to cleavage may occur through the grains (trans-crystalline) or at grain boundary (inter-crystalline).

b) shearing fractures that occur along the maximum tangential tension, while the fracture crack is inclined at 45 degrees to the direction in which tensile stress applies. The fracture is trans-crystalline with a matte-fibrous aspect.

On a macroscopic scale, fractures can be:

a) ductile, determined by the tangential stresses and produced by shearing. These can be identified micro-fractographically on the surface of fracture as some semi-spherical cavities called cups (dimples) appear.

b) brittle, i.e. cracks produced by cleavage characterized by fractures surfaces that occur perpendicular to the direction in which the tensile stress applies. On a macroscopic scale, if tensile stress are applied, three areas can be detected: the fibrous, the radial, and the edge shearing area.

A particular case of fracture is due to fatigue. When fatigue fractures occur in metallic materials, three areas can be distinguished at microstructure level: the crack initiation area (the crack propagates in ductile manner expanding over several grains); the fatigue fracture area (this area displays fatigue lines called streaks) where the fracture crack passes 
through the grains and displays a fiery aspect at macroscopic level; the final area is the one of the final fracture which can be brittle or ductile, displaying a granules-like aspect at macroscopic level.

Our studies approached the analysis of broken, ductile, fragile and fatigue surfaces of alloys (steel, cast iron, non-ferrous alloys) obtained both via SEM and OCT [7,8]. Following these analyses, we have demonstrated that OCT can replace SEM for the breakage surface analysis.

The aim of the present paper is to discuss these aspects and to give a few examples of such an analysis.

\section{MATERIALS AND METHODS}

\subsection{Analyzed materials}

In order to demonstrate the utility of the OCT method for fracture analysis, various types of metallic materials have been chosen in our studies [7,8]. In the present work, the following materials were considered: one subjected to ductile fracture (OLC 44) and two materials which typically brake in a brittle way: $\mathrm{Sn}-\mathrm{Sb}-\mathrm{Cu}$ antifriction alloy and ductile cast iron FGN 400-18 LT.

Microstructures of the following metallic materials have been analyzed after their subjection to fracture tests:

a) OL 44 rolled steel (STAS 500/2-80) having the following chemical composition: C $0.18 \%$, Mn $0.85 \%, \mathrm{~S} 0.04 \%$, P $0.05 \%$, and $\mathrm{Fe}$ for the rest. The microstructure of this steel which is mainly used for the manufacturing of welded metallic parts and protection wire meshes is made of ferrite and pearlite grains.

b) $\mathrm{Sn}-\mathrm{Sb}-\mathrm{Cu}$ antifriction alloy used for the manufacturing of internal combustion engine bearings. It has the following chemical composition: $\mathrm{Sb} 12 \%, \mathrm{Cu} 4 \%, \mathrm{Cd} \mathrm{1 \%}$, and for the rest $\mathrm{Sn}$. Its microstructure is made of a soft core of Sn solid solution containing small amounts of dissolved $\mathrm{Cu}$ and $\mathrm{Sb}$, as well as a hard phase of $\mathrm{SnSb}$ and $\mathrm{Cu} 3 \mathrm{Sn}$.

c) The ductile cast iron FGN 400-18 LT, used for the manufacturing of the rail wagon grease boxes, with the following chemical composition: $\mathrm{C} 3.43 \%$, Si $2.30 \%$, Mn $0.12 \%$, S $0.09 \%$, P $0.014 \%$. This chemical composition has led to the following mechanical properties: $\mathrm{Rm}=450 \mathrm{~N} / \mathrm{mm}^{2}$, resilience at $-20^{\circ} \mathrm{C}$ is $16 \mathrm{~J}$. The microstructure is suitable as the basic feritic mass surpassed $95 \%$, while the graphite falls within the required number nodules per $\mathrm{mm}^{2}$. This ductile cast iron was obtained using a thermal analysis system (ATAS).

\subsection{Sample processing method}

a) The OL 44, steel sample was subjected to tensile tests. Due to its chemical composition and microstructure this type of steel always breaks with a ductile fracture.

b) The $\mathrm{Sn}-\mathrm{Sb}-\mathrm{Cu}$ antifriction alloy sample was subjected to tensile testing until it broke. Due to its chemical composition and microstructure the fracture of this alloy is always brittle.

c) The ductile cast iron FGN 400-18 LT sample was subjected to tensile tests.

\subsection{SEM}

A high vacuum FEI Quanta 250 system with a secondary Everhard-Thomley electron detector has been utilized in all SEM analysis. In each SEM image, the values of the functioning parameters of this system are provided, including the pressure $(\mathrm{Pa})$ and the working distance (WD). The metallic samples have been examined at different magnitudes. Their mounting has been done using a binocular microscope, to assure the exposure of the investigated area to the electron beam.

\subsection{OCT system}

An in-house developed Swept Source (SS) OCT system, Master-Slave (MS) enhanced [31], with a center wavelength of $1310 \mathrm{~nm}$ has been utilized in the investigations. A detailed description of this system has been provided in [8].

\section{RESULTS AND DISCUSSION}

Figure 1 shows the fracture surfaces of a low carbon steel sample OL 44. This sample was subjected to ductile fracturing. In our initial study [7], we have performed an OCT imaging of such a sample using an OCT system with a (common) $10 \mu \mathrm{m}$ resolution. We have thus been able to demonstrate that the same selected metallic grains can be 
observed in both SEM and OCT images, but this comparison has proven difficult in [7] because of the rather small resolution of the OCT system. Thus, in [8] we have upgraded the optical part of the OCT system to achieve a superior 4 $\mu \mathrm{m}$ resolution. By doing so, we demonstrated that this is the optimal OCT resolution that allow for clearly observing the shape of metallic grains at the fracture surface, and thus to determine the type of fracture. Therefore, in the present study we present only such $10 \mu \mathrm{m}$ resolution OCT images. Figure 1(b) shows a clear image of grains that are broken in a ductile way.

Figure 2 shows the image of the fractured surface of $\mathrm{Sn}-\mathrm{Sb}-\mathrm{Cu}$ antifriction alloy. Figure 2(a) presents the SEM image of such a sample that broke in a brittle manner. It can be noticed that the sample broke without elongation, which is a characteristic feature of such a type of fracture.

Figure 2(b) shows the images of the fracture surfaces generated using, as in the previous case, only the most relevant images, i.e. those obtained with the OCT system with a $4 \mu \mathrm{m}$ resolution. The grains broke in a trans-granular manner, proving that the fracture was brittle.

(a)

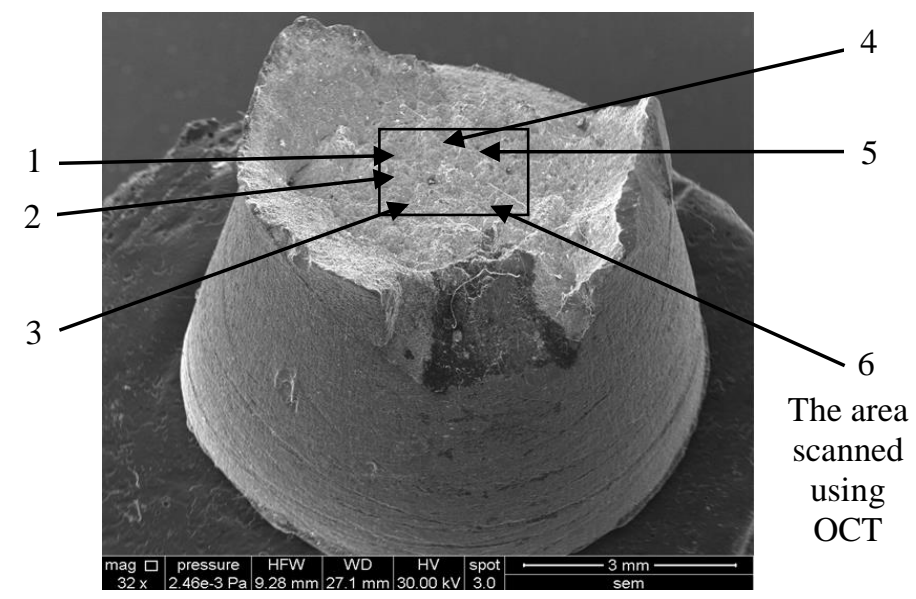

(b)

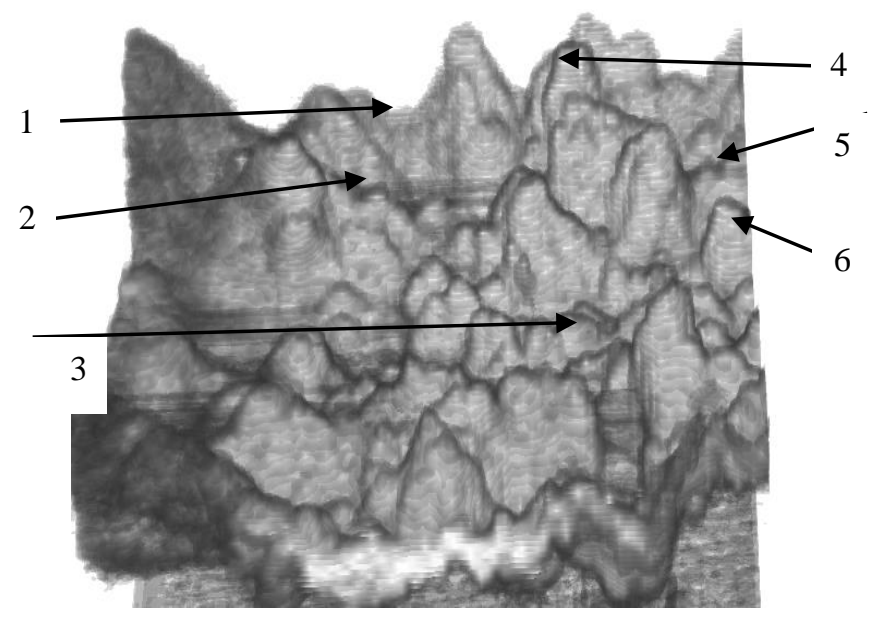

Figure 1. Imaging the fracture of an OL 44 steel sample: (a) frontal SEM overview of the entire sample, (b) OCT image (with a superior $4 \mu \mathrm{m}$ resolution) [8]. 


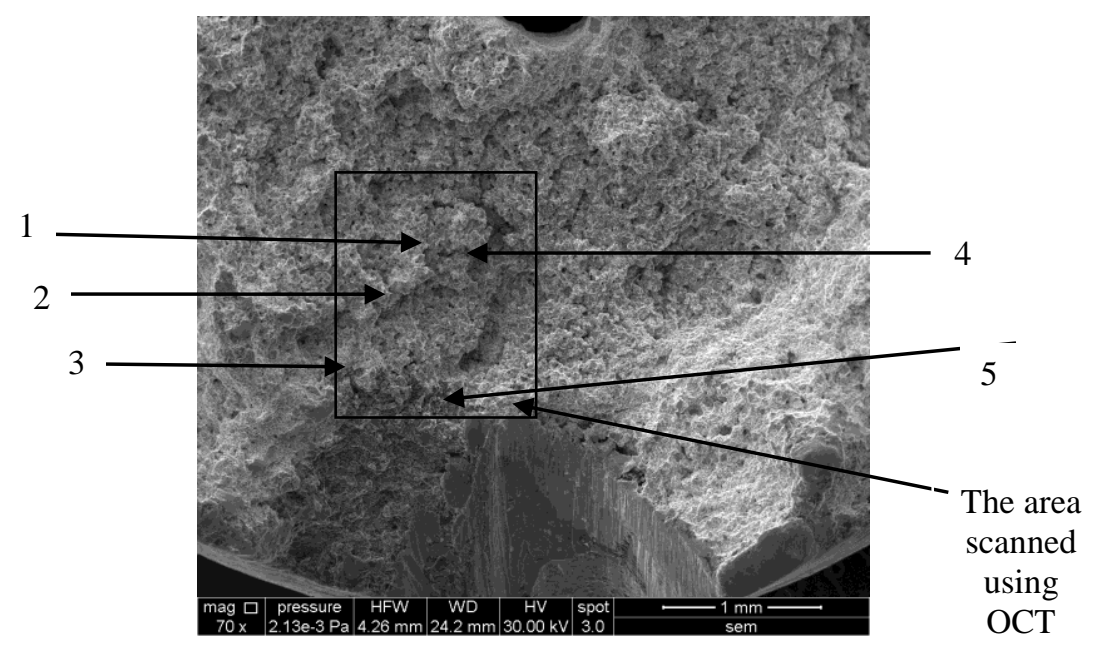

(a)

(b)

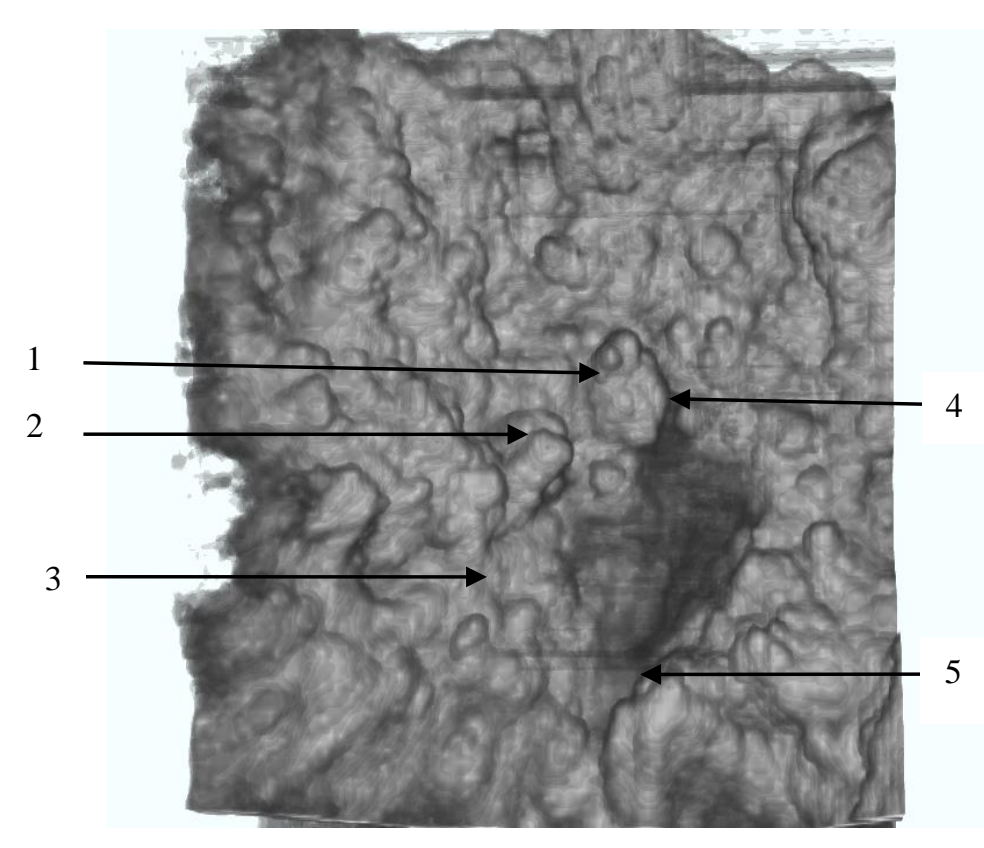

Figure 2. Imaging the fracture of Sn-Sb-Cu antifriction alloy: (a) frontal SEM overview of the entire sample; (b) OCT (with $4 \mu \mathrm{m}$ resolution) image of the same area.

Figure 3(a) shows the images of the fractured surface of the ductile cast iron FGN 400-18 LT T10 sample generated using SEM. The $1.5 \times 1.5 \mathrm{~mm}$ area analyzed further on using OCT has been outlined on this image. Figure 3(b) shows the image of the fracture surfaces generated using OCT. The FGN 400-RT nodular graphite cast iron has over 95\% ferrite inner microstructure. This microstructure gives the cast iron a 20\% elongation (A5) comparable to steel. In Fig. 3(b) only fragile broken grains appear. Cleavage fracture may occur through the crystal grain (as seen on grains 1 and 2, for example) or at crystal grains boundaries (as seen on grains 3 and 4, for example). 


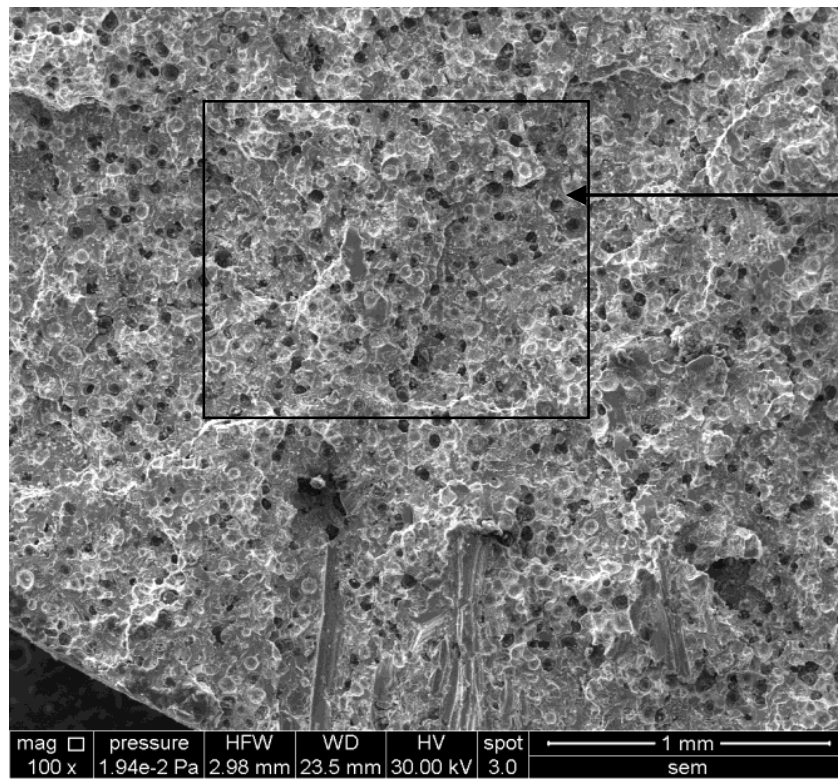

The area

scanned

using

OCT

(a)

(b)

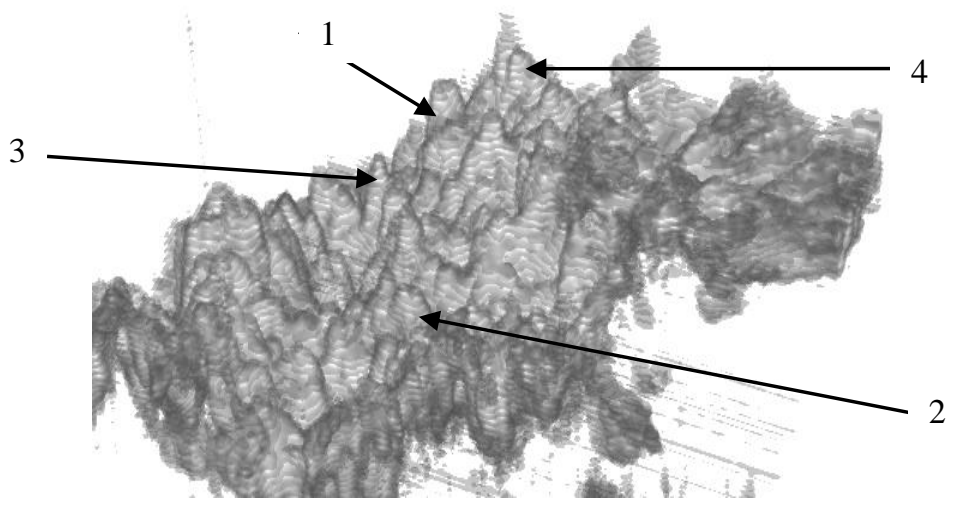

Figure 3. Imaging the fracture of a ductile cast iron FGN 400-18 LT: (a) SEM image of a portion of the sample, with the selected (smaller) area for OCT investigations; (b) OCT image (with a $4 \mu \mathrm{m}$ resolution).

\section{CONCLUSIONS}

1) The images obtained in the study show the fracture surfaces for three types of steels which broke in a ductile manner, and the fracture surfaces for a lamellar graphite cast iron and an antifriction alloy which broke in a brittle manner. These images were generated using two types of technologies, OCT and SEM. Other metallic materials were considered in the extended investigations performed in $[7,8]$.

Analyzing the images generated in the present paper and in [7,8] using a SEM with a 4 nm resolution and the images generated using an in-house developed SS-OCT system with a 10 and a $4 \mu \mathrm{m}$ resolution, it can be concluded that the OCT images are compatible with the SEM images for this type of application-and for a range of specific metallic materials.

The studies performed thus demonstrate that OCT can replace SEM in the analysis of metallic surfaces broken in a ductile or brittle manner.

2) Another advantage of the OCT method as compared to the SEM is that the former can generate the image of the entire (large) sample surface through consecutive scanning operations using an OCT mobile unit and handheld scanning probes [9-12]. These IR scanning operations do not destroy the metallic parts, which is an essential issue in the case of aviation, 
maritime, road or rail accidents, etc. In such cases the broken parts must not be destroyed. It is also essential in such forensic-type investigations to perform them in situ and for all parts and areas of interest.

3) These results may also prove useful for the (more complex) study of fatigue fractures of metallic materials, as demonstrated in [8].

\section{ACKNOWLEDGEMENTS}

This work was funded by the Romanian National Authority for Scientific Research, CNDI-UEFISCDI project PN-IIIP2-2.1-PED-2016-1937 (http://3om-group-optomechatronics.ro/). The dissemination of this study was also supported by The Polytechnic University of Timisoara, Department for International Relations, through the ISI Grant Program.

\section{REFERENCES}

[1] Geru, N., Marian B., Cosmeleata, G., Gurgu, C., [Analysis of metallic materials structure], Ed. Tehnica, Bucharest, 90-140 (1991).

[2] Goldstein, J., Newbury, D. E., Lyman, C. L., Echlin, P., Lifshin, E., Sawyer, L., [Scanning Electron Microscopy and X-ray Microanalysis], Third Edition, Springer Science + Business Media Inc., 128-192 (2003).

[3] Echlin, P., [Handbook of Sample Preparation for Scanning Electron Microscopy and X-Ray Microanalysis], Springer Science + Business Media Inc.,19-65 (2009).

[4] Williams, D. B., C. Barry Carter, [Transmission Electron Microscopy: A Textbook for Materials Science], Plenum Press, New York, (1996).

[5] Huang, D., Swanson, E. A., Lin, C. P., Schuman, J. S., Stinson, W. G., Chang, W., Hee, M. R., Flotte, T., Gregory, K., Puliafito, C. A., and Fujimoto, J. G., "Optical coherence tomography," Science 254(5035), 1178-1181 (1991).

[6] Wojtkowski, M., "High-speed optical coherence tomography: basics and applications," Applied Optics 49, D30-D61 (2010).

[7] Hutiu, Gh., Duma, V.-F., Demian, D., Bradu, A., and Podoleanu, A. Gh., "Surface imaging of metallic material fractures using optical coherence tomography," Appl. Opt. 53(26), 5912-5916 (2014).

[8] Hutiu, Gh., Duma, V.-F., Demian, D., Bradu, A., Podoleanu, A. Gh., "Assessment of ductile, brittle, and fatigue fractures of metals using optical coherence tomography," Metals 8(2), 117 (2018).

[9] Monroy, G. L., Won, J., Spillman, D. R., Dsouza, R., and Boppart, St. A., "Clinical translation of handheld optical coherence tomography: practical considerations and recent advancements," J. Biomed. Opt. 22(12), 121715 (2017).

[10] Demian, D., Duma, V.-F., Sinescu, C., Negrutiu, M. L., Cernat, R., Topala, I., Hutiu, Gh., Bradu, A., and Podoleanu, Gh. A., "Design and testing of prototype handheld scanning probes for optical coherence tomography," J. Eng. Med. 228(8), 743-753 (2014).

[11] Duma, V.-F., Dobre, G., Demian, D., Cernat, R., Sinescu, C., Topala, F. I., Negrutiu, M. L., Hutiu, G., Bradu, A., Podoleanu, A. G., "Handheld scanning probes for optical coherence tomography," Rom. Rep. Phys. 67, 1346-1358 (2015).

[12] Cogliati, A., Canavesi, C., Hayes, A., Tankam, P., Duma, V.-F., Santhanam, A., Thompson, K. P., and Rolland, J. P., "MEMS-based handheld scanning probe with pre-shaped input signals for distortion-free images in Gabor-Domain Optical Coherence Microscopy," Optics Express 24(12), 13365-13374 (2016).

[13] Awaja, F., Arhatari, B., Wiesauer, K., Leiss, E., Stifter, D., "An investigation of the accelerated thermal degradation of different epoxy resin composites using X-ray microcomputed tomography and optical coherence tomography," Polymer Degradation and Stability 94, 1814-1824 (2009)

[14] Manukyan, S., Sauer, H. S., Roisman, I. R., Baldwin, K. A., Fairhurst, D. F., Liang, H., Venzmer, J., Tropea, C., "Imaging internal flows in a drying sessile polymer dispersion drop using Spectral Radar Optical Coherence Tomography (SR-OC)," Journal of Colloid and Interface Science (2013).

[15] Price, J. H. P., Feng, X., Heidt, A. M., Brambilla, Horak, G. P, Poletti, F., Ponzo, G., Petropoulos, P., Petrovich, M., Shi, J., Ibsen, M., Loh, W. H., Harvey, N., Rutt, H. N., Richardson, D. J., "Supercontinuum generation in non-silica fibers," Optical Fiber Technology 18, 327-344 (2012).

[16] Schell, J. S. U., M. Renggli, G. H., van Lenthe, M., Ermanni, P., "Micro-computed tomography determination of glass fibre reinforced polymer meso-structure," Composites Science and Technology 66, 2016-2022 (2006). 
[17] Wiesauer, A. D., Dufau, S., Gotzinger, E., Pircher, M., Hitzenberger, C. D., Stifter, D., "Non-destructive quantification of internal stress in polymer materials by polarisation sensitive optical coherence tomography," Acta Materialia 53, 2785-2791 (2005).

[18] Thrane, L., Jørgensen, T. M., Jørgensen, M., Krebs, F. C., "Application of optical coherence tomography (OCT) as a 3-dimensional imaging technique for roll-to-roll coated polymer solar cells," Solar Energy Materials \& Solar Cells 97 $181-187$ (2012).

[19] Braza, A. K. S., Bernardo B. C., Braz, R., Gomes, A. S. L., "Evaluation of crack propagation in dental composites by optical coherence tomography, Dental Materials 25, 74-79 (2009).

[20] Queiroz de Melo Monteiro, G., Montesa, M. A. J. R., Gomes, A. S. L., Motac, C. B. O., Sérgio, L., Freitas, A. Z., "Marginal analysis of resin composite restorative systems using optical coherence tomography," Dental Materials 27 213-223 (2011).

[21] Turki, A., Bakhsha, B., Sadrb, A., Shimadaa, Y., Junji Tagamia, B., Yasunori S., "Non-invasive quantification of resin-dentin interfacial gaps using optical coherence tomography: Validation against confocal microscopy," Dental Materials 27, 915-925 (2011).

[22] Canjau, S., Todea, C., Negrutiu, M. L., Sinescu, C., Topala, F. I., Marcauteanu, C., Manescu, A., Duma, V.-F., Bradu, A., Podoleanu, A. Gh., "Optical Coherence Tomography for Non-Invasive ex vivo Investigations in Dental Medicine - a Joint Group Experience (Review)," Modern Technologies in Medicine 7(1), 97-115 (2015).

[23] Czajkowsk, J., Pryka, T., Alarousu, E., Palosaari, J., Myllyla, R., "Optical Coherence Tomography as a Method of Quality Inspection for Printed Electronics Products,” Opt. Review 17(3), 257-262 (2010).

[24] Serrels, K. L., Renner, M. K., Reid, D. T., "Optical coherence tomography for non-destructive investigation of silicon integrated-circuits," Microelectronic Engineering 87, 1785-1791 (2010).

[25] Stepien, R., Buczynski, R., Pysz, D., Kujawa, I., Filipkowski M. M., Diduszko R., "Development of thermally stable tellurite glasses designed for fabrication of microstructured optical fibers," Journal of Non-Crystalline Solids 357, 873-883 (2011).

[27] Jonathan, E., "Non-contact and non-destructive testing of silicon V-grooves: A non-medical application of optical coherence tomography (OCT)," Optics and Lasers in Engineering 44, 1117-1131 (2006).

[28] Su-Hwan Kim, S-H., Jee-Hyun K., Shin-Won, K., "Nondestructive defect inspection for LCDs using optical coherence tomography, Displays 32, 325-329 (2011).

[29] Nemeth Robert Gahleitner, A., Hannesschlager, G., Giselher Pfandler, G., Leitner, M., "Ambiguity-free spectraldomain optical coherence tomography for determining the layer thicknesses in fluttering foils in real time," Optics and Lasers in Engineering 50 (2012).

[30] Liang, H., Gomez Cid, M., Cucu, R. G., Dobre, G. M., Podoleanu, A. Gh., Saunders, D., "En-face optical coherence tomography - a novel application of non-invasive imaging to art conservation, Opt. Express 13, 6133-6144 (2005).

[31] Podoleanu, A. Gh. and Bradu, A., "Master-slave interferometry for parallel spectral domain interferometry sensing and versatile 3D optical coherence tomography," Opt. Express 21, 19324-19338 (2013). 